\title{
Persistent organic pollutants in river food webs: influence of trophic position and degree of heterotrophy
}

\author{
Olof Berglund, Per Nyström, and Per Larsson
}

\begin{abstract}
We investigated how the degree of autotrophy/heterotrophy and organism trophic position influenced the bioaccumulation of polychlorinated biphenyls (PCBs) in 10 benthic river food webs consisting of terrestrial detritus, periphyton, invertebrates, and age-0 brown trout (Salmo trutta) in southern Sweden. Concentrations of PCBs increased with trophic position, estimated from $\delta^{15} \mathrm{~N}$ and $\delta^{13} \mathrm{C}$, on a dry weight basis (ng. $\mathrm{g}^{-1}$ dry weight) but not on a lipid weight basis (ng. $\mathrm{g}^{-1}$ lipid). PCB biomagnification factors between the first and second trophic levels (invertebrates/ periphyton and invertebrates/detritus) ranged between 0.3 and 2.3 and between the second and third levels (trout/invertebrates) between 0.3 and 2.0 on a lipid weight basis. The mean proportion of carbon ultimately derived from terrestrial sources, $\alpha$, was $0.82 \pm 0.19$ for invertebrates and $0.67 \pm 0.28$ for trout. Contrary to our hypothesis, PCB concentrations in trout were positively related to $\alpha\left(r^{2}=0.58-0.77, p<0.05\right)$. As $\alpha$ and the periphyton density $\left(\mathrm{g} \mathrm{C}^{-2} \mathrm{~m}^{-2}\right)$ in the rivers was positively related $\left(r^{2}=0.88, p<0.01\right)$, we propose that this relationship was due to an increased retention and exposure of PCBs to trout in rivers with low grazing pressure and high periphyton density.
\end{abstract}

\begin{abstract}
Résumé : Nous avons déterminé dans quelle mesure le degré d'autotrophie/hétérotrophie et la position trophique des organismes influencent la bioconcentration des biphényls polychlorés (BPC) dans 10 réseaux alimentaires benthiques de rivière comprenant le détritus terrestre, le périphyton, les invertébrés et les truites brunes (Salmo trutta) d'âge 0 dans le sud de la Suède. Les concentrations de BPC augmentent en fonction de la position trophique lorsqu'elles sont estimées à partir de $\delta^{15} \mathrm{~N}$ et de $\delta^{13} \mathrm{C}$ en masse sèche $\left(\mathrm{ng} \cdot \mathrm{g}^{-1}\right.$ de masse sèche), mais pas en masse lipidique (ng. $\mathrm{g}^{-1}$ de lipides). Les facteurs de bioamplification (BMF) entre les premier et second niveaux trophiques (invertébrés/périphyton et invertébrés/détritus) varient de 0,3 à 2,3 et entre les second et troisième niveaux (truite/invertébrés) de 0,3 à 2,0 sur la base de la masse lipidique. La proportion moyenne de carbone dérivée en fin de compte des sources terrestres, $\alpha$, est de $0,82 \pm 0,19$ chez les invertébrés et de 0,67 $\pm 0,28$ chez les truites. Contrairement à notre hypothèse, les concentrations de BPC chez la truite sont en corrélation positive avec $\alpha\left(r^{2}=0,58-0,77, p<0,05\right)$. Comme $\alpha$ est relié directement $\left(r^{2}=0,88, p<0,01\right)$ à la densité du périphyton $\left(\mathrm{g} \mathrm{C} \cdot \mathrm{m}^{-2}\right)$ dans les rivières, nous croyons que cette relation est due à une rétention accrue et une exposition plus grande des BPC chez les truites dans les rivières à faible pression de broutage et à forte densité de périphyton.
\end{abstract}

[Traduit par la Rédaction]

\section{Introduction}

The contamination of waters with persistent organic pollutants (POPs) has occurred over the last four decades and is still a major environmental issue in aquatic environments. Although levels of certain compounds appear to have decreased after prohibition in many industrialized countries in the last two decades, the decrease today seems to have leveled off and high concentrations, especially in aquatic predators, are still of concern (Bignert et al. 1998; Nyman et al.

Received 19 November 2003. Accepted 30 March 2005.

Published on the NRC Research Press Web site at

http://cjfas.nrc.ca on 6 September 2005.

J17851

O. Berglund ${ }^{1}$ and P. Larsson. Chemical Ecology and Ecotoxicology, Department of Ecology, Lund University, S-223 62, Lund, Sweden.

P. Nyström. Limnology, Department of Ecology, Lund University, S-223 62, Lund, Sweden.

${ }^{1}$ Corresponding author (e-mail: Olof.Berglund@ekol.lu.se).
2002). Also, new POPs have replaced old ones and these new compounds are now found in increasing levels in aquatic environments (Rayne et al. 2003). Another environmental concern in aquatic environments is the eutrophication caused by excessive load of nutrients from anthropogenic activities. The main effect of eutrophication on aquatic ecosystems is an increase of primary production. In rivers, it has been demonstrated that the addition of phosphorus shifts the system from heterotrophy, where detritus of terrestrial origin is the dominating carbon source, to autotrophy, where aquatic primary producers are the dominating carbon source (Peterson et al. 1985). Earlier, we have shown that POPs in river biota increase with increasing trophic status of the river (Berglund et al. 1997). We suggested that a shift from terrestrial carbon sources to aquatic might be partly responsible for the increase of POP concentrations, possibly owing to initial differences in POP concentrations in the primary producers. These differences at the first trophic level may persist in higher trophic levels of the aquatic food web owing to food chain transfer of POPs. POPs are often found in high concentrations in the top predators of aquatic food chains at 
concentrations above those predicted from equilibrium partitioning between the water and the organism (Fisk et al. 2001). This phenomenon has been attributed to the influence of food and the process of biomagnification where piscivorous fish reach higher concentrations than the prey owing to gastrointestinal (GI) magnification (Connolly and Pedersen 1988; Gobas et al. 1999). If this mechanism applies to all trophic transfers between consumers and food in the food web, it could lead to food chain bioaccumulation, an increase in concentration with each step in the food chain. The studies on biomagnification and food chain bioaccumulation of POPs in aquatic environments have predominantly been focused on predatory pelagic fish or mammals in lakes and marine environments. Benthic food webs including the base and lower trophic levels, and in particular those in lotic environments, have thus far been largely neglected, with a few exceptions (Galassi et al. 1994; Hill and Napolitano 1997; Zaranko et al. 1997).

The ratio of stable isotopes of nitrogen $\left(\delta^{15} \mathrm{~N}\right)$ can be used to estimate trophic position because the $\delta^{15} \mathrm{~N}$ of a consumer is typically enriched by $3-4 \%$ o relative to its diet (Peterson and Fry 1987). Therefore, estimates of $\delta^{15} \mathrm{~N}$ of the different components in food webs are often used to investigate the effect of trophic position and biomagnification on POP concentrations in food webs. The ratio of carbon isotopes $\left(\delta^{13} \mathrm{C}\right)$, however, seems to change little in the transfer between trophic levels (Peterson and Fry 1987; France and Peters 1997) and may therefore be used to evaluate the sources of origin of carbon in an organism when the isotopic signatures of the sources are different. Terrestrial and aquatic primary producers have been found to differ in $\delta^{13} \mathrm{C}$ signature (Peterson and Fry 1987), and therefore, $\delta^{13} \mathrm{C}$ signatures of the components in aquatic food webs may be used to estimate the influence of heterotrophy where carbon is derived from terrestrial (allochthonous) sources versus autotrophy where the carbon is derived from aquatic (autochthonous) sources in the system. There is considerable variation, however, among ecosystems in the $\delta^{15} \mathrm{~N}$ and $\delta^{13} \mathrm{C}$ of the base of the food web from which organisms draw their nitrogen and carbon, and also, there may be more than one base food source (Nyström et al. 2003). By constructing mixing models and combining $\delta^{15} \mathrm{~N}$ and $\delta^{13} \mathrm{C}$ signatures of the different base food sources and consumers, it may be possible to calculate the influence of different food sources and trophic positions of consumers that are comparable across different ecosystems (Post 2002).

Here, we wanted to investigate the influence of the degree of heterotrophy/autotrophy on POP concentrations in the river food chains by testing the hypothesis that POP levels are higher in aquatic autotrophs than in terrestrial detritus, and if so, these differences are preserved in the autotrophic food chain. The degree of heterotrophy/autotrophy, $\alpha$, was determined from the $\delta^{13} \mathrm{C}$ ratios in detritus of terrestrial origin, periphyton, invertebrates, and age-0 brown trout (Salmo trutta). Further, we wanted to investigate the food chain bioaccumulation of POPs in rivers to test the hypothesis that POP concentrations in river organisms increase with increasing trophic position of the organism and if the concentrations in the food chain could be explained by equilibrium partitioning, steady-state biomagnification, or non-steady-state bioaccumulation. We investigated polychlorinated biphenyl
(PCB) concentrations in the food chains of 10 streams and rivers in southern Sweden. The compartments of the food chains in each river were detritus of terrestrial origin, periphyton, invertebrates, and age- 0 trout. The trophic position of the compartments were assigned as traditional discrete levels $\left(1,2\right.$, and 3 ), on a continuous scale from $\delta^{15} \mathrm{~N}$ measurements, and from combining $\delta^{13} \mathrm{C}$ and $\delta^{15} \mathrm{~N}$ values in the compartments and in the different food sources in a mixing model as described by Post (2002).

\section{Materials and methods}

\section{Stream characteristics and sample collection}

The sampling was conducted from July to October 1998. Ten different rivers in southern Sweden $\left(13^{\circ} \mathrm{E}, 56^{\circ} \mathrm{N}\right)$ were selected for the experiment. The rivers were chosen on a trophic gradient determined by the total phosphorus concentrations in the water. The rivers are situated in a defined geographical area that receives similar amounts of organochlorines via atmospheric deposition with no known point sources (Berglund et al. 1997; Backe et al. 2000). The river stretches where the sampling was performed were similar in length $(25 \mathrm{~m})$ and riffle parts of the rivers were always included. River characteristics are presented in Table 1. Periphyton was sampled on ceramic tiles. Twenty $20 \mathrm{~cm} \times$ $20 \mathrm{~cm}$ tiles were placed in each of the 10 rivers. The tiles were left for colonization for 60 days from July to October. At the end of the colonization period, the tiles were scraped with a brush into one precleaned container giving one pooled sample for each river. The periphyton density was calculated as milligrams of organic carbon per square metre. Organic carbon content was determined for terrestrial primary producers, periphyton, and detritus with an LECO CR12 carbon analyzer (Merry and Spounser 1988). One site was not included in the analysis of periphyton density, as the tiles were destroyed during the experiment. At this site, periphyton for stable isotope analysis was sampled by scraping stones from the river. After periphyton sampling, two or three individuals of age- 0 trout were sampled with electrofishing, detritus of terrestrial origin (one pooled sample consisting mainly of leaves at varying stages of decomposition) was collected from the river, and terrestrial primary producers (one pooled sample consisting of leaves from alder (Alnus spp.), European beech (Fagus sylvatica), and sage (Salix spp.) and Vällingebäcken and Saxån grasses and leaves) were collected immediately adjacent to the river. Aquatic invertebrates were sampled by thoroughly kicksampling the river stretches. All invertebrates from the kicksampling were collected to represent potential food for age-0 trout and to give a crude representation of the invertebrate community in the rivers. The invertebrates were identified to group and then pooled after freeze-drying for PCB and stable isotope analysis. The invertebrate samples were in all rivers but one, Vällingebäcken, dominated by the shredder Gammarus pulex (70-100\% of total dry weight) with varying amounts of snail (grazers) $(>10 \%)$, leaches (invertebrate predators) $(>15 \%)$, and mayflies (grazers) $(>5 \%)$. The invertebrate sample from Vällingebäcken was composed of leaches $(\sim 25 \%)$, snails $(\sim 70 \%)$, and mayflies $(\sim 5 \%)$. Gammarus pulex and mayflies are important food sources for trout, while snails and leaches are part of the trout diet 
but are not considered as important (e.g., Dahl 1998). All samples were frozen and then freeze-dried before analysis. Water samples for total phosphorus analysis were taken three different times during the periphyton colonization (beginning, middle, and end). Total phosphorus concentrations were analyzed with standard methods (digestion with peroxodisulphate) at the Department of Ecology, Lund University.

\section{Sample preparation and analysis}

The methods for sample preparation and analysis are described in detail elsewhere (Bremle et al. 1995). Briefly, PCBs in whole trout, invertebrates, periphyton, detritus, and terrestrial primary producers were extracted in a modified Soxhlet apparatus with a mixture of acetone and $n$-hexane. The lipid content of trout, invertebrates, periphyton, detritus, and terrestrial primary producers was determined gravimetrically. Octachloronaphthalene and pentachlorobenzene were used as internal standard and chromatographic standard, respectively. Concentrated extracts were cleaned and fractionated on acid-base double-layer silicagel columns. Samples were analyzed for PCBs by capillary gas chromatography with an electron capture detector (Varian $3400 \mathrm{cx}$ ) with a split/splitless injector, 25-m DB5 quartz capillary column (inner diameter $0.25 \mathrm{~mm}$ ). PCB components were identified according to Mullin et al. (1984) and Schulz et al. (1989). A total of 65 peaks of PCB congeners were identified and quantified in the different samples. Domain 19 (IUPAC No. 52), D32 (No. 66/95), D38 (No. 90/101), D54 (No. 132/153/105), D58 (No. 160/138/158), D72 (No. 180), and D84 (No. 194) were used for further statistical analysis, as they were present in $100 \%$ of the samples in high concentrations and represent a wide range in lipophilicity (log octanol-water partitioning coefficient $\left(\log K_{\mathrm{OW}}\right)$ 5.8-7.8) (Hawker and Connell 1988) and degree of chlorination (tetra- to octa-chlorinated).

\section{Quality control}

The analytical performance was regularly controlled with pesticide standards and PCB standards (Aroclor 1242 and Clophen A60). Extraction efficiency of the internal standard octachloronaphthalene was $113 \pm 8 \%$. Samples were not corrected for recovery. A procedural blank was run in parallel with every batch of eight samples. All blank concentrations of the seven PCBs used for statistical analysis were $<6 \%$ of the levels found in the samples and no blank correction was made.

\section{Stable isotope measurements}

Carbon and nitrogen isotope ratios were analyzed in lipidextracted samples of detritus, periphyton, invertebrates, and age-0 trout. The stable isotopes were analyzed on a continuous-flow IRMS (20-20 stable isotope analyser) (Europa Scientific Ltd., Crewe, UK) interfaced with an elemental analyzer unit (ANCA-NT system, solid-liquid preparation module) (Europa Scientific Ltd.) at the Department of Forest Ecology, Swedish University of Agricultural Sciences, Umeå, Sweden. A detailed description of the isotope analysis is given in Ohlsson and Wallmark (1999). Briefly, $1-5 \mathrm{mg}$ of a finely ground sample was placed in tinfoil containers and masses were determined. The samples were then 
combusted completely in an oxidizing column (chromium oxide, copper oxide, and silver wool) and into which a pulse of oxygen was added concurrent with sample introduction. The carbon and nitrogen content of the sample was quantitatively converted into $\mathrm{CO}_{2}$ and $\mathrm{N}_{2}$, respectively. The $\mathrm{CO}_{2}$ and $\mathrm{N}_{2}$ formed were separated using a gas chromatography column and transferred with helium carrier gas through a thermal conductivity detector and then to the IRMS inlet. The notation is the relative difference in isotopic ratio between the samples and known standards (e.g., Peterson and Fry 1987; Ohlsson and Wallmark 1999).

To calculate the degree of heterotrophy, $\alpha$, we used the equation from Post (2002):

$$
\alpha=\left(\delta^{13} C_{c}-\delta^{13} C_{p}\right) /\left(\delta^{13} C_{d}-\delta^{13} C_{p}\right)
$$

where $\delta^{13} C_{c}$ is the isotopic signature of the consumer, $\delta^{13} C_{p}$ is the signature of periphyton, and $\delta^{13} \mathrm{C}_{\mathrm{d}}$ is the signature of detritus of terrestrial origin. When all carbon in the consumer is derived from terrestrial sources, $\alpha=1$, and when all carbon is derived from aquatic sources, $\alpha=0$.

To calculate a trophic position for a consumer comparable across all systems, we removed the effect of the between-site variability in the isotopic signatures at the base of the food webs and assumed a two-source food web with detritus of terrestrial origin and periphyton as the bases of the two food webs. The trophic position was calculated using the equation from Post (2002):

$$
\begin{aligned}
\text { Trophic position }=\lambda+\left\{\delta^{15} \mathrm{~N}_{\mathrm{c}}-\left[\delta^{15} \mathrm{~N}_{\mathrm{d}} \alpha\right.\right. \\
\left.\left.+\delta^{15} \mathrm{~N}_{\mathrm{p}}(1-\alpha)\right]\right\} / \Delta_{n}
\end{aligned}
$$

where $\lambda$ is the trophic position of the organism used to estimate $\delta^{15} \mathrm{~N}_{\text {base }}$ (e.g., $\lambda=1$ for the primary producers used in this study) and $\Delta_{n}$ is the enrichment in $\delta^{15} \mathrm{~N}$ per trophic level (set to $3.4 \%$ in this study). The $\alpha$ is the proportion of nitrogen in the consumer ultimately derived from detritus of terrestrial origin and assuming that the movement of nitrogen and carbon through the food web is similar, identical to $\alpha$ from eq. 1.

\section{Statistical analysis}

All concentration and periphyton biomass data were $\log _{10^{-}}$ normalized before statistical analysis to obtain a normal distribution ( $Z$ scores, $<5 \%$ of the data points $>2$ or $<-2$ ). Biomagnification factors $\left(\mathrm{BMF}_{\text {consumer/food }}\right)$ for the different PCBs were calculated by dividing the dry weight (nanograms per gram dry weight) or lipid weight (nanograms per gram lipid) PCB concentration in the consumer with the dry weight or lipid weight concentration in the putative food.

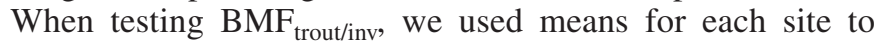
avoid pseudoreplication. Simple regression analyses tested the relationships between lipid content and PCB concentrations and the relationships between $\mathrm{PCB}$ concentrations or $\mathrm{BMFs}$ of the invertebrates or age- 0 trout and trophic position or degree of heterotrophy $(\alpha)$. One-way ANOVAs with Tukey-Kramer post hoc tests $(\alpha=0.05)$ tested differences between dependent variables (lipid content, PCB concentrations, and BMFs) with the different compartments (terrestrial primary producers, detritus, periphyton, invertebrates, and age-0 trout) as the independent variable. ANCOVAs tested the significance of lipid content as covariate on PCB concentrations (nanograms per gram dry weight) with food web compartments as factors. One-sample $t$ tests with hypothesized difference $=0$ tested differences in log BMFs from zero. For repeated $t$ tests, we used sequential Bonferroni tests by the Dunn-Šidák method to calculate critical $\alpha^{\prime}$ values (Sokal and Rohlf 1995). All tests were performed using the StatView ${ }^{\circledR}$ package (SAS Institute Inc., Cary, North Carolina).

\section{Results}

\section{Carbon source}

The mean proportion of carbon ultimately derived from terrestrial sources, $\alpha$, was $0.82 \pm 0.19$ for invertebrates and $0.67 \pm 0.28$ for trout. At several sites (five for invertebrates and three for trout), the estimated $\alpha$ value was $>>1$, i.e., the mixing model could not be used owing to the fact that the isotope ratios of periphyton and terrestrial detritus were overlapping or fell outside the limits of the invertebrate or trout isotope signatures (Nyström et al. 2003). These sites were excluded from statistical analyses involving $\alpha$.

On a dry weight basis, higher $K_{\mathrm{OW}}$ PCB concentrations in trout were positively related to $\alpha$, and all PCB concentrations were positively related to $\alpha$ on a lipid weight basis (Table 2). However, $\alpha$ was positively correlated with the periphyton density in the rivers (Fig. 1), which has earlier been shown to predict the organochlorine uptake in rivers (Berglund 2003). We removed the effect of periphyton density by performing simple regression analysis between periphyton density and PCB concentrations (simple regressions, $r^{2}=0.40-0.58, \mathrm{df}=8, p=0.02-0.07$ ) and performed new regression analyses on $\alpha$ and the residuals from the former regressions. When the effect of periphyton density was removed, no relationships between $\alpha$ and PCB concentrations were found (simple regressions, $\mathrm{df}=6, p>0.05$ ).

PCB concentrations did not differ greatly between the allochthonous (detritus and riparian vegetation) and autochthonous (periphyton) carbon sources. Generally, concentrations increased from terrestrial riparian vegetation $\leq$ detritus < periphyton, but differences were only statistically significant when expressed on a lipid or organic carbon basis (ANOVA, $\mathrm{df}=2,24$, Tukey-Kramer post hoc tests, $p<0.05$ ) (Table 3). Mean terrestrial primary producer/periphyton concentration ratios ranged from 0.4 to 1.6 on a dry weight basis, from 0.1 to 0.4 on a lipid weight basis, and from 0.1 to 0.4 on an organic carbon basis, and mean detritus/periphyton ratios ranged from 0.7 to 1.8 on a dry weight basis, from 0.6 to 1.0 on a lipid weight basis, and from 0.3 to 0.6 on an organic carbon weight basis, with decreasing ratios with increasing $K_{\mathrm{OW}}$ of the compounds.

\section{PCB concentrations and trophic position}

Dry weight normalized concentrations of the seven PCB congeners were related to the lipid content of the samples from all the compartments in the food web (simple regressions, $r^{2}=0.26-0.68, \mathrm{df}=57, p<0.05$ ) (Fig. 2). The degree of explanation and regression coefficients showed a bellshaped relationship with the $\log K_{\mathrm{OW}}$ of the compounds. However, within each compartment of the food web, we found no significant relationships between PCB concentrations and lipid content (the compartment $\times$ lipid content interaction terms and the effect of lipid content in ANCOVAs 
Table 2. Regression analysis between mean heterotrophy, $\alpha$, of brown trout (Salmo trutta) (calculated from eq. 1) as independent variable and mean log concentration of the selected seven PCBs from the seven investigated rivers as dependent variables.

\begin{tabular}{lllll}
\hline & \multicolumn{3}{c}{ Regression } \\
Dependent variable & df & coefficient & $r^{2}$ & $p$ \\
\hline PCB52 (dw) & 6 & 1.00 & 0.46 & 0.095 \\
PCB66/95 (dw) & 6 & 1.00 & 0.40 & 0.130 \\
PCB90/101 (dw) & 6 & 0.99 & 0.44 & 0.110 \\
PCB132/153/105 (dw) & 6 & 0.85 & 0.56 & 0.052 \\
PCB160/138/158 (dw) & 6 & 0.96 & 0.55 & 0.057 \\
PCB180 (dw) & 6 & 0.91 & 0.59 & 0.044 \\
PCB194 (dw) & 6 & 1.00 & 0.56 & 0.052 \\
PCB52 (lw) & 6 & 1.25 & 0.63 & 0.033 \\
PCB66/95 (lw) & 6 & 1.25 & 0.58 & 0.048 \\
PCB90/101 (lw) & 6 & 1.24 & 0.63 & 0.033 \\
PCB132/153/105 (lw) & 6 & 1.10 & 0.77 & 0.010 \\
PCB160/138/158 (lw) & 6 & 1.21 & 0.73 & 0.014 \\
PCB180 (lw) & 6 & 1.16 & 0.76 & 0.010 \\
PCB194 (lw) & 6 & 1.25 & 0.68 & 0.022 \\
\hline
\end{tabular}

Note: Three rivers were omitted, as $\alpha$ were $>>1$. df, regression coefficients, $r^{2}$ values, and $p$ values are presented for each of the regression analyses with log concentrations of PCBs expressed on a dry weight (dw) basis and lipid weight (lw) basis.

were not significant, $p>0.05$ ) (Fig. 2). Lipid content differed between the three trophic levels: trout $(n=28)$ had the highest, $11.0 \pm 3.1 \%$, followed by invertebrates $(n=10)$, $6.1 \pm 2.9$, and detritus $(n=10)$ and periphyton $(n=10)$ the lowest, $2.6 \pm 1.2 \%$ and $0.9 \pm 0.3 \%$, respectively (ANOVA, df $=3,54, p<0.01$; Tukey-Kramer post hoc tests, $p<0.05$ ) (Table 4). Trout length differed between the river sites (ANOVA, df $=9,18, p<0.01$ ). PCB concentrations were not related to individual trout length either on a dry weight or on a lipid weight basis (simple regressions, $\mathrm{df}=27, p>$ $0.05)$.

On a dry weight basis, PCB concentrations generally increased with increasing trophic level, but when concentrations were expressed on a lipid weight basis, no increases were found (Fig. 3). The geometrical means of biomagnification factors for trout/invertebrates $\left(\mathrm{BMF}_{\text {trout/inv }}\right)$ for the different PCBs ranged from 0.6 to 3.7 on a dry weight basis and from 0.3 to 2.0 on a lipid weight basis. $\log \mathrm{BMF}_{\text {trout/inv }}$ showed a bell-shaped relationship with the $\log K_{\mathrm{OW}}$ of the PCBs (Figs. $4 a$ and $4 b$ ). On a dry weight basis, log $\mathrm{BMF}_{\text {trout/inv }}$ for higher $K_{\mathrm{OW}}$ PCBs were $>0$ (Fig. $4 a$ ), while on a lipid weight basis, only one PCB was $>0$ and the two lower $K_{\mathrm{OW}}$ PCBs were $<0$ (Fig. $4 b$ ). The geometrical means of biomagnification factors for invertebrates/detritus $\left(\mathrm{BMF}_{\text {inv/detr }}\right)$ and invertebrates/periphyton $\left(\mathrm{BMF}_{\text {inv/per }}\right)$ for the different $\mathrm{PCBs}$ ranged from 2.7 to 5.9 for $\mathrm{BMF}_{\text {inv/detr }}$ on a dry weight basis, from 1.1 to 2.3 for $\mathrm{BMF}_{\text {inv/detr }}$ on a lipid weight basis, from 2.0 to 7.7 for $\mathrm{BMF}_{\text {inv/per }}$ on a dry weight basis, and from 0.3 to 1.2 on a lipid weight basis. We found no relationships between either $\log \mathrm{BMF}_{\text {inv/detr }}$ or $\log$ $\mathrm{BMF}_{\text {inv/per }}$ and $\log K_{\mathrm{OW}}$ of the PCBs (Figs. $4 c$ and $4 d$ ). On a dry weight basis, all $\log \mathrm{BMF}_{\text {inv/detr }}$ and $\log \mathrm{BMF}_{\text {inv/per }}$ were $>0$ except for $\log \mathrm{BMF}_{\text {inv/per }}$ for the two highest $K_{\mathrm{OW}}$ PCBs (Fig. 4c). On a lipid weight basis, only $\log \mathrm{BMF}_{\text {inv/per }}$ for the two highest $K_{\mathrm{OW}}$ PCBs were different from 0 (Fig. $4 d$ ).
Fig. 1. Regression analysis on the relationship between degree of heterotrophy, $\alpha$, in age-0 brown trout (Salmo trutta) and log periphyton density in the rivers $\left(y=1.7 x-0.8, r^{2}=0.88, \mathrm{df}=\right.$ $5, p<0.01)$. Each point represents the mean $\alpha$ of two or three trout from one river. Three sites where $\alpha>1$ and one site where periphyton density could not be measured was excluded from the analysis.

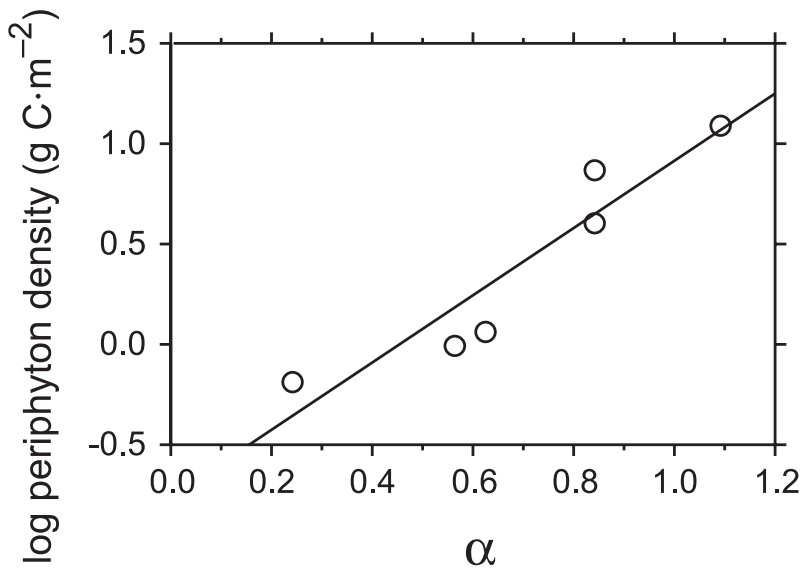

Fig. 2. Regression analysis between lipid content (\% of dry weight) and $\log$ PCB132/153/105 concentrations in all the samples (solid circles, detritus of terrestrial origin; open circles, periphyton; open squares, invertebrates; solid squares, age-0 brown trout (Salmo trutta)) from the investigated rivers $(y=8.9 x+$ $0.24, r^{2}=0.59$, df $\left.=57, p<0.01\right)$.

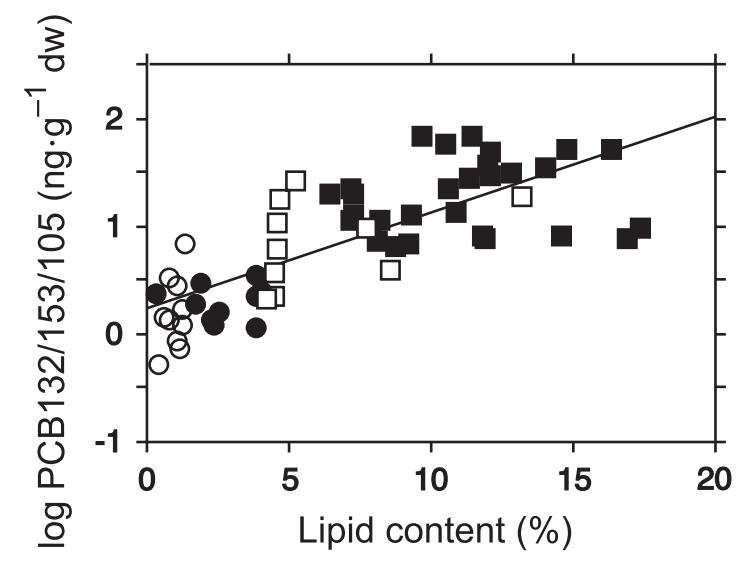

The $\delta^{15} \mathrm{~N}$ ratios in the different compartments of the food webs varied between sites. At the base of the food webs, the $\delta^{15} \mathrm{~N}$ ratios in detritus ranged from $0.3 \%$ to $11 \%$, and periphyton $\delta^{15} \mathrm{~N}$ from $6.4 \%$ to $16 \%$. Also, trout $\delta^{15} \mathrm{~N}$ varied between sites, ranging from $7.5 \%$ to $19 \%$, although the within-site range was never more than $1.5 \%$ (Table 4$)$. The within-site difference in $\delta^{15} \mathrm{~N}$ between trout and invertebrates was $2.6 \%$, which was significantly different from $0 \%$ but not from 3.4\%o (paired $t$ tests, df $=9$, with hypothesized differences $=0$ and 3.4, respectively, and $p<0.01$ and $p>0.1$, respectively). Estimation of trophic position (eq. 2) gave a mean trophic position of $2.3 \pm 0.8$ for invertebrates and $3.1 \pm 0.9$ for trout. On a dry weight basis, PCB concentrations were positively related to the trophic position of all samples from all compartments (simple regressions, $r^{2}=$ $0.11-0.48$, df $=57, p<0.05$ ) with regression coefficients 
Table 3. Differences in PCB concentrations expressed on a dry weight, lipid weight, and organic carbon weight basis between terrestrial primary producers (TPP), detritus of terrestrial origin (D), and periphyton (P).

\begin{tabular}{|c|c|c|c|c|c|c|c|c|c|}
\hline \multirow[b]{2}{*}{ PCB No. } & \multicolumn{3}{|c|}{ Dry weight } & \multicolumn{3}{|c|}{ Lipid weight } & \multicolumn{3}{|c|}{ Organic carbon weight } \\
\hline & TPP & $\mathrm{D}$ & $\mathrm{P}$ & TPP & $\mathrm{D}$ & $\mathrm{P}$ & TPP & $\mathrm{D}$ & $\mathrm{P}$ \\
\hline 52 & - & - & - & $<\mathrm{P}$ & - & $>\mathrm{TPP}$ & $<\mathrm{P}$ & $<\mathrm{P}$ & $>\mathrm{D}>\mathrm{TPP}$ \\
\hline 90/101 & - & - & - & $<\mathrm{P}$ & - & $>\mathrm{TPP}$ & $<\mathrm{P}$ & $<\mathrm{P}$ & $>\mathrm{D}>\mathrm{TPP}$ \\
\hline $132 / 153 / 105$ & - & - & - & $<\mathrm{P}$ & - & $>\mathrm{TPP}$ & $<\mathrm{P}$ & $<\mathrm{P}$ & $>\mathrm{D}>\mathrm{TPP}$ \\
\hline $160 / 138 / 158$ & - & - & - & $<\mathrm{P}$ & - & $>\mathrm{TPP}$ & $<\mathrm{P}$ & $<\mathrm{P}$ & $>\mathrm{D}>\mathrm{TPP}$ \\
\hline
\end{tabular}

Note: ">" or "<" denotes a significant difference between the different carbon sources and "_ " denotes no significant difference $($ ANOVA, df $=2,24$, Tukey-Kramer post hoc tests, $p<0.05)$.

Table 4. Means $\pm 1 \mathrm{SD}$ and maximum-minimum (in parentheses) from the 10 investigated rivers of lipid content (\% of dry weight), organic carbon content ( $\%$ of dry weight), $\delta^{15} \mathrm{~N}(\%), \delta^{13} \mathrm{C}(\%)$, degree of heterotrophy $(\alpha)$, trophic position, and PCB concentrations (ng.g dry weight $\left.{ }^{-1}\right)$ in the four investigated compartments: detritus of terrestrial origin $(n=10)$, periphyton $(n=10)$, invertebrates $(n=$ $10)$, and age-0 brown trout (Salmo trutta) $(n=28)$.

\begin{tabular}{lcccr}
\hline & Detritus & Periphyton & Invertebrates & Trout \\
\hline Lipids & $2.6 \pm 1.2(0.3-4.0)$ & $0.9 \pm 0.3(0.4-1.3)$ & $6.1 \pm 2.9(4.1-13.2)$ & $11.0 \pm 3.1(6.4-17.3)$ \\
Organic carbon & $35 \pm 6.0(28-45)$ & $13 \pm 6.0(6-22)$ & - & - \\
$\delta^{15} \mathrm{~N}$ & $6.3 \pm 3.5(0.3-11.1)$ & $10.2 \pm 2.9(6.4-15.9)$ & $10.8 \pm 3.0(4.5-14.9)$ & $13.2 \pm 2.6(7.5-19.0)$ \\
$\delta^{13} \mathrm{C}$ & $-28.7 \pm 1.0(-30.0$ to -27.0$)$ & $-27.3 \pm 5.5(-33.9$ to -17.2$)$ & $-28.5 \pm 1.3(-31.5$ to -27.0$)$ & $-28.1 \pm 1.9(-32.3$ to -25.7$)$ \\
$\alpha$ & 1 & 0 & $0.82 \pm 0.19(0.63-1.03)$ & $0.67 \pm 0.28(0.23-1.11)$ \\
Trophic position & 1 & 1 & $2.3 \pm 0.8(1.3-3.6)$ & $3.1 \pm 0.9(2.0-5.0)$ \\
PCB52 & $0.9(0.6-1.6)$ & $0.7(0.2-1.9)$ & $4.7(2.4-8.7)$ & $2.9(1.0-24.3)$ \\
PCB66/95 & $1.3(0.6-2.6)$ & $0.9(0.2-3.8)$ & $4.7(1.3-20.5)$ & $5.2(1.3-45.2)$ \\
PCB90/101 & $1.3(0.6-2.8)$ & $0.9(0.3-3.5)$ & $5.3(1.4-23.4)$ & $7.6(2.3-55.4)$ \\
PCB132/153/105 & $2.0(1.2-3.5)$ & $1.6(0.5-7.1)$ & $8.1(2.1-26.3)$ & $19.7(6.6-70.6)$ \\
PCB160/138/158 & $2.4(1.4-4.1)$ & $1.8(0.6-8.4)$ & $2.5(0.7-12.0)$ & $20.0(5.8-87.4)$ \\
PCB180 & $0.9(0.6-1.6)$ & $1.2(0.3-6.3)$ & $0.5(0.2-1.7)$ & $9.4(2.8-34.1)$ \\
PCB194 & $0.1(0.04-0.2)$ & $0.2(0.07-1.3)$ & & $1.3(0.2-4.4)$ \\
\hline
\end{tabular}

and degree of explanation showing a bell-shaped relationship with the $\log K_{\mathrm{OW}}$ of the compound. On a lipid weight basis, no such relationships were found. When invertebrates and trout were analyzed separately, no relationship was found between trophic position and PCB concentrations on either a dry weight basis or a lipid weight basis (simple regressions, $\mathrm{df}=9$ and $\mathrm{df}=27$, respectively, $p>0.05)$.

\section{Discussion}

\section{Carbon source and PCB concentrations}

We hypothesized that differences in carbon source between the systems would influence POP concentrations. The differences in PCB concentrations between terrestrial and aquatic primary producers in our study were low. In general, dry weight concentrations were similar; concentrations in periphyton were higher than in terrestrial primary producers on an organic carbon and lipid weight basis and also higher than in detritus of terrestrial origin on a lipid weight basis. However, the differences were small; ratios of terrestrial primary producers/periphyton concentrations were between 0.1 and 0.4. Therefore, any influence from the differences in carbon source on the PCB concentrations in the food chains is probably not from initial differences in concentrations between the terrestrial and aquatic primary producers.
A shift in carbon source or shift from heterotrophy to autotrophy is expected with an increase in nutrients and (or) an increase of stream order or watershed area or change in predation regime (Peterson et al. 1985; Finlay 2001; Nyström et al. 2003). With increased stream order or nutrient concentrations, autotrophy increases and $\alpha$ decreases. In the rivers of this study, the proportion of carbon ultimately derived from terrestrial sources, $\alpha$, varied between $63 \%$ to $103 \%$ for invertebrates and between $23 \%$ to $111 \%$ for trout, indicating a higher utilization of autotrophic carbon sources by trout than by the invertebrates in our samples. The relative importance of terrestrial (allochthonous) versus aquatic (autochthonous) carbon sources to river food webs is highly variable between systems. The River Continuum Concept (Vannote et al. 1980) states that there is a longitudinal change from heterotrophic headwater streams to autotrophic midorder streams/rivers to heterotrophic large rivers, but the primary energy source supporting overall metazoan production in mid- to higher trophic levels of most rivers (fourth order and greater) may be autochthonous primary production entering food webs via algal-grazer pathways (Thorp and Delong 2002). In the rivers of this study, which fall into the category of headwater streams and midorder streams/rivers, the autochthonous production did not seem to be the primary energy source, as our mixed model (eq. 2) gave that carbon 
Fig. 3. Plots showing log concentrations of the seven PCBs in the four investigated compartments: detritus of terrestrial origin $(\mathrm{D})(n=$ 10), periphyton (P) $(n=10)$, invertebrates (I) $(n=10)$, and age-0 brown trout (Salmo trutta) $(\mathrm{T})(n=28)$. Concentrations are expressed on a dry weight basis (open circles) and on a lipid weight basis (solid circles). Each point represents the mean and bars show \pm 1 SD. The letters above the boxes, D, P, I, and T, denote compartments with significantly different concentrations (ANOVAs, Tukey-Kramer post hoc tests, $p<0.05$ ).
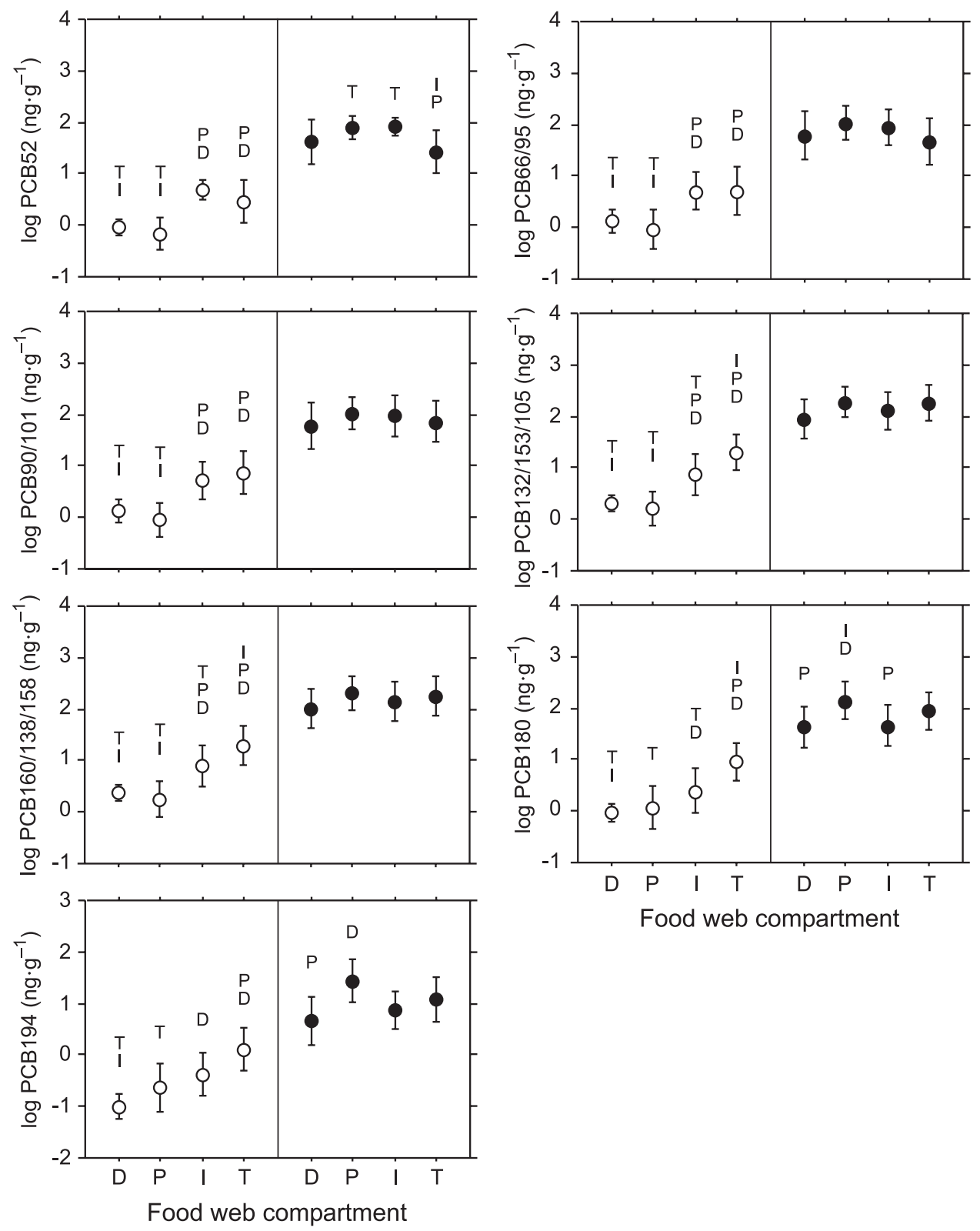

of terrestrial origin made up on average $82 \%$ of the invertebrate carbon and $67 \%$ of the trout carbon. A reliance of terrestrial carbon in the invertebrate communities of this study is expected, as they were largely composed of the shredder G. pulex, a species that feeds mainly on leaf litter (Sutcliffe et al. 1981). However, in the largest river in the study, Höje å, the trout carbon was primarily derived from autochthonous sources, and terrestrial carbon contributed with as little as $23 \%$ (but with $77 \%$ in the invertebrates). Thus, the relative influence of terrestrial and algal carbon sources in the streams and rivers in this study seems to follow the River Continuum Concept. The estimations of $\alpha$ resulted in unrealistic values $(\alpha>>1)$ for invertebrate samples from five of the rivers and for trout from three of the rivers. These unre-

alistic values were produced when $\delta^{13} \mathrm{C}$ values of the detritus of terrestrial origin and periphyton were either lower (in all cases but two) or higher than of the consumers. The variability of $\delta^{13} \mathrm{C}$ in periphyton is known to be very high, and in many cases, it may be impossible for stable isotope analysis to discriminate between allochthonous and autochthonous carbon dependency in stream ecosystems (Nyström et al. 2003).

Contrary to our hypothesis, PCB concentrations in trout were positively related to $\alpha$ or increasing degree of heterotrophy. This may be due to an increased retention of PCB in the rivers caused by a higher density of periphyton (Fig. 5). With increasing autotrophy or reliance of periphyton as carbon source of the food webs, the density of periphyton de- 
Fig. 4. $\left(a\right.$ and $b$ ) Relationships between the log octanol-water partitioning coefficients $\left(K_{\mathrm{OW}}\right)$ of the seven PCBs and log biomagnification factors (BMFs) between age-0 brown trout (Salmo trutta) and invertebrates expressed on a dry weight basis (Fig. $4 a$ ) and lipid weight basis (Fig. $4 b)$. ( $c$ and $d$ ) Relationships between the $K_{\mathrm{OW}}$ of the seven PCBs and log BMFs between invertebrates and periphyton (open circles) and between invertebrates and detritus (solid circles) expressed on a dry weight basis (Fig. $4 c$ ) and on a lipid weight basis (Fig. $4 d$ ). Each point in all figures represents the mean BMF of the 10 rivers investigated $(n=10$ for BMF trout/inv, $\mathrm{BMF}_{\text {inv/per }}$, and $\mathrm{BMF}_{\text {inv/detr }}$ ). Bars show $\pm 1 \mathrm{SD}$. * Significant difference of log BMFs from 0 (one-sample $t$ test with hypothesized difference $=0, \alpha=0.05)$.
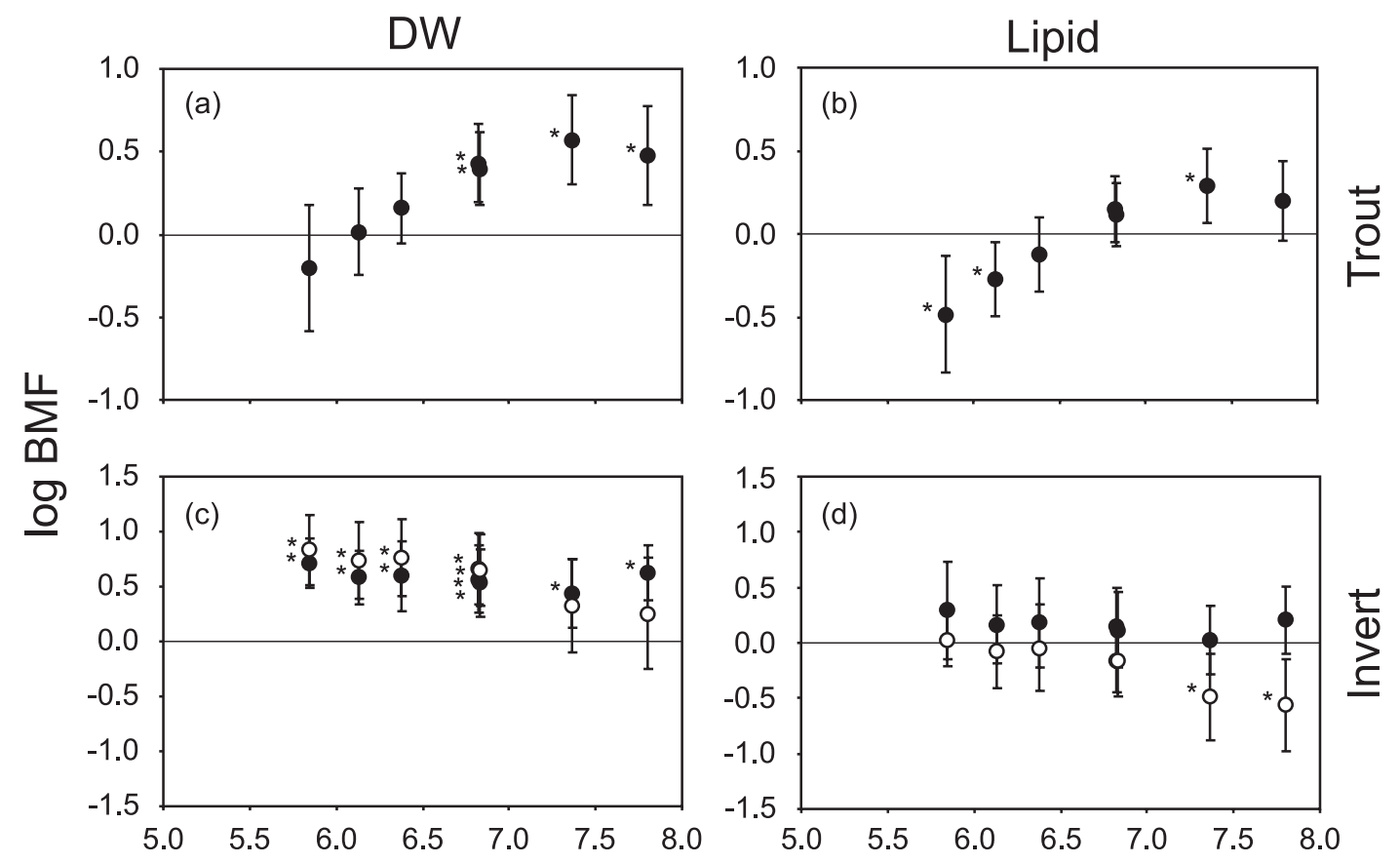

$\log K_{\text {ow }}$

creases owing to increased grazing (Nyström and McIntosh 2003). Periphyton density in rivers is influenced by nutrients, light, stream velocity, and grazing (Rosemond et al. 2000). The relative importance of these factors may vary, but nutrient limitation is of less importance in rivers of this nutrient concentration range (Chételat et al. 1999). In the rivers in this study, we found no influence of nutrients, light, or stream velocity on periphyton biomass (Berglund 2003); however, we could not directly estimate the influence of grazing pressure in this study, as our sampling of invertebrates was not quantitative. POP concentrations in river biota have been shown to increase with increasing periphyton density (Berglund 2003). An increased periphyton density in the river will increase retention of POPs and increase the probability of uptake in biota, as predicted by the spiraling theory (Newbold et al. 1983; Stewart et al. 1993). The spiraling of compounds in rivers with unidirectional flow of water combines cycling with retention and accumulation in the ecosystem (Essington and Carpenter 2000). The retention increases with increasing periphyton density, which constitutes a large immobile surface area with which the POPs can associate, decreasing their downward transport and increasing the probability of uptake in biota. In lakes, an increase in primary producer biomass has been suggested to lower POP concentrations by biomass dilution (Taylor et al. 1991), but no such effect was found in these rivers (Berglund 2003). When the effect of periphyton density was removed, the correlation between $\alpha$ and PCB in this study disappeared. Thus, the carbon source or degree of heterotrophy/autotrophy may influence PCB concentrations in river food webs, but contrary to our hypothesis, the concentrations did not increase with increasing autotrophy owing to higher concentrations in aquatic primary producers than in terrestrial primary producers. Instead, concentrations decreased with increasing autotrophy, possibly as an indirect effect of increased grazing of periphyton that reduces periphyton biomass and thus reduces retention and uptake of PCBs in the river food web (Fig. 5).

\section{Trophic position and stable isotopes}

The between-site variation of $\delta^{15} \mathrm{~N}$ and $\delta^{13} \mathrm{C}$ was high in all compartments including the bases, detritus and periphyton, of the food webs, an observation made in several stream studies (France 1995). The range in $\delta^{15} \mathrm{~N}$ was around $10 \%$ in each compartment, which would represent more than two trophic levels assuming an enrichment of 3\%o-4\%o between trophic levels. The within-site variation in age-0 trout was low, however; the mean range was $0.7 \%$ and never exceeded $1.7 \%$. The compartment signatures of $\delta^{13} \mathrm{C}$ also varied between sites. The variation was greatest within the aquatic primary producer compartment of the food chain as observed in several other studies (e.g., France 1995; Finlay 2001). Periphyton $\delta^{13} \mathrm{C}$ ranged from $-34 \%$ o to $-17 \%$, but, interestingly, that of terrestrial primary producers also varied 
Fig. 5. Conceptual figure of the relationships between the benthic functional groups, degree of heterotrophy, $\alpha$, and POP concentrations in brown trout (Salmo trutta). Broken arrows indicate relationships not explicitly tested in this study. The higher POP concentrations in trout with higher $\alpha$ may be indirectly caused by an increase of the heterotrophy/autotrophy ratio in the system. A decrease of the grazer/shredder ratio and decreased grazing pressure may lead to higher periphyton density, higher retention of POPs, and higher POP concentrations in trout as demonstrated by Berglund (2003).

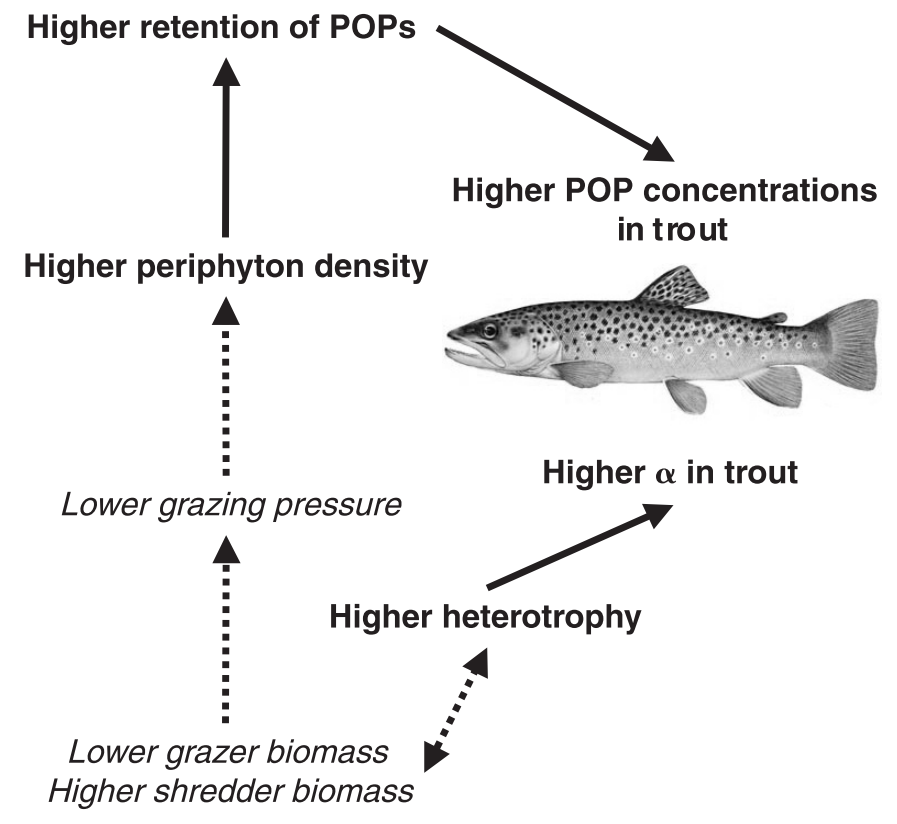

considerably, between $-32 \%$ and $-26 \%$ (results not shown). Apparently, spatial variation in isotopic signatures can be substantial even within a fairly restricted geographical area like in this study $\left(5000 \mathrm{~km}^{2}\right)$. To apply a stable isotope technique to multiple-system food webs like the rivers in this study, one requires obtaining an isotopic baseline at the base of the food webs in each system. In this study, we used the equations developed by Post (2002) to calculate trophic positions in a two-source food web where we used periphyton and detritus of terrestrial origin as the bases of the two food webs. To integrate temporal variation in isotopic signatures, Post (2002) recommended using primary consumers, and preferably long-lived, to quantify isotopic baselines. We chose to use primary producers and detritus, as there were no two distinct groups of primary consumers representing the autotrophic and heterotrophic food webs at all sites and also our chosen food webs had a low number of theoretical trophic levels with age- 0 trout as our top predator. However, as the differences in age were small between the organisms in our compartments, temporal variation should not differ considerably between compartments in our food webs.

The mean estimated trophic position of all sites was 2.3 for invertebrates and 3.1 for age- 0 trout, which indicates that the isotopic baseline quantification from eq. 2 was valid. The discrete trophic-level classification would predict invertebrates as primary consumers (level 2) and age-0 trout as secondary consumers (level 3 ). It is also reasonable for invertebrates to have a trophic position slightly higher than 2 and age-0 trout higher than 3 , as a few invertebrates (leaches) in our samples are considered predatory (i.e., secondary consumers). However, the between-site variation of the estimated trophic position was high. The trophic position of invertebrates ranged from 1.3 to 3.6 and of age-0 trout from 2.0 to 5.0. It seems unlikely that age-0 trout would occupy trophic level 5 of the food web. Hence, the model seemed to estimate mean trophic positions using all sites satisfactory, but the sample sizes of the base of the food chain were probably too small $(n=1)$ to give reliable absolute estimates at each individual site.

\section{PCB concentrations and food chain bioaccumulation}

The support for food chain bioaccumulation of PCBs in these benthic, low trophic levels in rivers was not conclusive. On a dry weight basis, the PCBs with $\log K_{\mathrm{OW}}$ values between 6.5 and 7.5 increased in concentration with the trophic position of the organisms in our river food webs. Mean concentrations of the seven selected PCBs were similar in detritus and periphyton and increased in invertebrates and the concentrations of PCB132/153/105, PCB160/138/158, and $\mathrm{PCB} 180$ were highest in age- 0 trout. The concentrations of the seven selected PCBs in the samples were also positively related to the trophic position of the samples estimated using the data from the stable isotope analyses. Here, also, the slope and strength of the relationship were highest for PCB132/153/105, PCB160/138/158, and PCB180. However, this pattern was only observed when PCB concentrations were expressed on a dry weight basis. When concentrations were expressed on a lipid weight basis, no increase of PCB concentrations with trophic position was found. Lipid content explained $26 \%-68 \%$ of the variation in PCB concentrations (nanograms per gram dry weight) in all samples. We did not find relationships between lipid content and PCB concentrations within each compartment of the food webs. However, several biotic and abiotic factors differing between the river sites may affect the PCB concentrations in both water and organisms and therefore confound the lipid-PCB relationships (Berglund 2003), even though the input of PCBs to the river watersheds should be similar, as atmospheric deposition is similar over the region (Backe et al. 2000). Lipid content is one of the most important factors in explaining uptake of lipophilic POPs like PCBs in aquatic organisms, and lipid weight based concentrations are used when comparing accumulation in different organisms or systems, as the relative difference among lipid weight based concentrations is a good approximation of the relative differences in fugacity (Kucklick and Baker 1998; Mackay and Fraser 2000). The lipid content increased in the river food chains, from primary producers to primary consumers, and the highest lipid content was found in the predators, which has been proposed to be one of the factors explaining increasing levels of POPs in aquatic food chains (LeBlanc 1995). Therefore, we chose to use lipid weight based PCB concentrations in our food chains to examine food chain bioaccumulation and GI magnification. Consequently, PCB concentrations expressed on a dry weight basis increased with trophic level both when expressed with discrete levels and when calculated on a continuous scale from $\delta^{15} \mathrm{~N}$ and $\delta^{13} \mathrm{C}$, but when expressed as nanograms per gram lipid, no relationship was found between PCB concentration and trophic level. Thus, 
the increasing lipid content in the food chain could explain the apparent increase of concentration with increasing organism trophic position.

To investigate steady-state biomagnification caused by GI magnification, we calculated biomagnification factors for each trophic transfer by dividing the concentration in the consumer with the concentration in the putative food. In this study, biomagnification factors for the seven selected PCBs between invertebrates and detritus $\left(\mathrm{BMF}_{\text {inv/detr }}\right)$ or periphyton $\left(\mathrm{BMF}_{\text {inv/per }}\right)$ were between 0.3 and 2 on a lipid weight basis, and biomagnification factors in the second trophic transfer between trout and invertebrates $\left(\mathrm{BMF}_{\text {trout/inv }}\right)$ ranged from 0.3 to 2.0 on a lipid weight basis. Only PCB 180 had biomagnification factors higher than 1, and PCB52 and PCB66/95 had biomagnification factors lower than 1 . These biomagnification factors are low compared with other studies on piscivorous fish (3-5; Russell et al. 1995) or planktivorous fish (1-3; Hoekstra et al. 2003). However, the results are similar to those found in planktonic food chains in lakes (Berglund et al. 2000) where there was no biomagnification in the first trophic transfer between zooplankton and phytoplankton and only an increase (biomagnification factors = 1.5-3.0) in concentrations of the PCBs with $\log K_{\mathrm{OW}}>6.5$ in the second trophic transfer between zooplankton and planktivorous young-of-the-year roach (Rutilus rutilus). Thus, PCBs were magnified on a dry weight basis but not on a lipid weight basis in the first trophic transfer between periphyton and detritus, and invertebrates and the biomagnification factors were independent of the $K_{\mathrm{OW}}$ values of the PCBs. Hence, the accumulation in invertebrates corresponds to an equilibrium partitioning of PCBs either with food or with water. The biomagnification factors in the second trophic transfer were related to the $K_{\mathrm{OW}}$ of the compounds. Biomagnification factors were lower than 1 for PCBs with $\log K_{\mathrm{OW}}<6.5$ and higher than or not different from 1 for PCBs with $\log K_{\mathrm{OW}}>6.5$. Therefore, equilibrium partitioning with food cannot explain the accumulation in age-0 trout. According to the GI magnification model (Gobas et al. 1999), chemicals with a $\log K_{\text {OW }}<5$ will not magnify from food to consumer owing to a high rate of chemical elimination, and Sijm et al. (1992) showed that the elimination rates decreased with increasing size or decreasing growth rate of the consumer. The biomagnification factors $<1$ indicate that age-0 trout are not in equilibrium or steady state with their environment, which may be caused by high growth dilution owing to high growth rates, and the biomagnification factors $>1$ also indicate nonequilibrium, which may be caused by GI magnification. A GI magnification at non-steady-state conditions may thus explain the shape of the $\mathrm{BMF}_{\text {trout/inv }}-K_{\mathrm{OW}}$ relationship. The fact that lipid content did not explain PCB concentrations of organisms within each compartment of the food chain could suggest that equilibrium or steady state is not reached between the organisms and the environment or the food in the rivers of this study. It seems that to observe food chain accumulation as a result of GI magnification, organisms with lower growth rates (i.e., closer to steady state) should be studied.

We used PCB concentrations on a lipid weight basis when testing biomagnification and calculating biomagnification factors in all compartments of the food chain. Although it is often assumed that in plants and algae, POP accumulation is a passive process governed by the compounds' affinity for the lipids of plant and algae, controversy remains with regard to the importance of the lipid fraction as the accumulation site of POPs in the biota, especially for plants and algae (Skoglund and Swackhamer 1999). Rather than the lipid fraction, the organic carbon fraction is often used to normalize POPs in plants and algae (Skoglund and Swackhamer 1999). If other nonlipid organic materials play an important role in the accumulation of POPs in primary producers, normalization to lipids may lead to overestimations of the primary producer concentrations entered in the biomagnification factor calculations. In our study, the lipid content and organic carbon content in periphyton and detritus were related $\left(f_{\mathrm{oC}}=0.1+9 f_{\text {lip }}, r^{2}=0.75\right)$. Thus, the organic carbon fraction $\left(f_{\mathrm{oC}}\right)$ was one order of magnitude higher than the lipid fraction $\left(f_{\text {lip }}\right)$ in detritus and periphyton. However, like lipids, the organic carbon fraction could not predict PCB concentrations within each of the two compartments in this study. Lipid content has been shown to accurately predict PCB accumulation in both fish and invertebrates (Kucklick and Baker 1998; Berglund et al. 2000). Therefore, we used dry matter and lipid rather than carbon-normalized PCB concentrations for all compartments when testing food chain bioaccumulation and biomagnification factors in our food chains.

In conclusion, several ecological and chemical factors influence the accumulation of POPs in aquatic organisms. The degree of heterotrophy/autotrophy in rivers may influence accumulation of POPs through indirect effects from the dominating functional groups of the benthic community. Contrary to what we predicted in this study, a high degree of autotrophy decreased PCB concentrations in age- 0 trout. The high grazing pressure in the algae/grazer-dominated autotrophic systems may suppress periphyton densities, thereby reducing the retention and exposure of lipophilic contaminants to the river biota.

Concentrations of POPs in aquatic food webs, and in particular at the lower trophic levels with organisms of similar size and age, are not determined only by the trophic position of the organisms. In this study, lipid content was the best predictor of PCB concentrations in the food chain periphyton/detritus - invertebrates - age-0 trout, and lipid weight based concentrations did not increase with trophic position. However, lipid content could not predict PCB concentrations within each trophic level, and on a dry weight basis, PCB concentrations increased with trophic position. We did find indications of GI magnification of PCBs in age0 trout but not in invertebrates. Possibly, the age- 0 trout in this study were not in steady state with their environment owing to high growth rates, probably higher than for fish used in other GI magnification and food chain bioaccumulation studies.

\section{Acknowledgements}

Funding for Olof Berglund was provided by the Knut and Alice Wallenberg Foundation and MISTRA. The authors thank two anonymous reviewers and an Associate Editor for comments on an earlier version on this manuscript. 


\section{References}

Backe, C., Larsson, P., and Okla, L. 2000. Polychlorinated biphenyls in the air of southern Sweden - spatial and temporal variation. Atmos. Environ. 34: 1481-1486.

Berglund, O. 2003. Periphyton density influences organochlorine accumulation in rivers. Limnol. Oceanogr. 48: 2106-2116.

Berglund, O., Larsson, P., Brönmark, C., Greenberg, L., Eklöv, A., and Okla, L. 1997. Factors influencing organochlorine uptake in age-0 brown trout (Salmo trutta) in lotic environments. Can. J. Fish. Aquat. Sci. 54: 2767-2774.

Berglund, O., Larsson, P., Ewald, G., and Okla, L. 2000. Bioaccumulation and differential partitioning of polychlorinated biphenyls in freshwater, planktonic food webs. Can. J. Fish. Aquat. Sci. 57: 1160-1168.

Bignert, A., Olsson, M., Persson, W., Jensen, S., Zakrisson, S., Litzen, K., Eriksson, U., Häggberg, L., and Alsberg, T. 1998. Temporal trends of organochlorines in northern Europe, 19671995. Relation to global fractionation, leakage from sediments and international measures. Environ. Pollut. 99: 177-198.

Bremle, G., Okla, L., and Larsson, P. 1995. Uptake of PCBs in fish in a contaminated river system: bioconcentration factors measured in the field. Environ. Sci. Technol. 29: 2010-2015.

Chételat, J., Pick, F.R., Morin, A., and Hamilton, P.B. 1999. Periphyton biomass and community composition in rivers of different nutrient status. Can. J. Fish. Aquat. Sci. 56: 560-569.

Connolly, J.P., and Pedersen, C.J. 1988. A thermodynamic evaluation of organic chemical accumulation in aquatic organisms. Environ. Sci. Technol. 22: 99-103.

Dahl, J. 1998. The impact of vertebrate and invertebrate predators on a stream benthic community. Oecologia, 117: 217-226.

Essington, T.E., and Carpenter, S.R. 2000. Nutrient cycling in lakes and streams: insights from comparative analysis. Ecosystems, 3: 131-143.

Finlay, J.C. 2001. Stable-carbon-isotope ratios of river biota: implications for energy flow in lotic food webs. Ecology, 82: 10521064.

Fisk, A.T., Hobson, K.A., and Norstrom, R.J. 2001. Influence of chemical and biological factors on trophic transfer of persistent organic pollutants in the Northwater Polynya marine food web. Environ. Sci. Technol. 35: 732-738.

France, R.L. 1995. Carbon-13 enrichment in benthic compared to planktonic algae: foodweb implications. Mar. Ecol. Prog. Ser. 124: $307-312$.

France, R.L., and Peters, R.H. 1997. Ecosystem differences in the trophic enrichment of ${ }^{13} \mathrm{C}$ in aquatic food webs. Can. J. Fish. Aquat. Sci. 54: 1255-1258.

Galassi, S., Guzzella, L., Battegazzore, M., and Carrieri, A. 1994. Biomagnification of $\mathrm{PCBs}, p, p^{\prime}$-DDE, and $\mathrm{HCB}$ in the River Po ecosystem (northern Italy). Ecotoxicol. Environ. Saf. 29: 174186.

Gobas, F.A.P.C., Wicockson, J.B., Russell, R.W., and Haffner, G.D. 1999. Mechanism of biomagnification in fish under laboratory and field conditions. Environ. Sci. Technol. 33: 133-141.

Hawker, D.W., and Connell, D.W. 1988. Octanol-water partitioning coefficients of polychlorinated biphenyl congeners. Environ. Sci. Technol. 22: 382-387.

Hill, W.R., and Napolitano, G.E. 1997. PCB congener accumulation by periphyton, herbivores, and omnivores. Arch. Environ. Contam. Toxicol. 32: 449-455.

Hoekstra, P.F., O’Hara, T.M., Fisk, A.T., Borgå, K., Solomon, K.R., and Muir, D.C.G. 2003. Trophic transfer of persistent organochlorine contaminants (OCs) within an Arctic marine food web from the southern Beaufort-Chukchi seas. Environ. Pollut. 124: 509-522.

Kucklick, J.R., and Baker, J.E. 1998. Organochlorines in Lake Superior's food web. Environ. Sci. Technol. 32: 1192-1198.

LeBlanc, G.A. 1995. Trophic-level differences in the bioconcentration of chemicals: implications in assessing environmental biomagnification. Environ. Sci. Technol. 29: 154-160.

Mackay, D., and Fraser, A. 2000. Bioaccumulation of persistent organic chemicals: mechanisms and models. Environ. Pollut. 110: 375-391.

Merry, R.H., and Spounser, L.R. 1988. The measurments of carbon in soils using a microprocessor-controlled resistance furnace. Commun. Soil Sci. Plant Anal. 19: 707-720.

Mullin, M.D., Pochini, C.M., McCridle, S., Romkes, M., Safe, S.H., and Safe, L.M. 1984. High-resolution PCB analysis: synthesis and chromatographic properties of all 209 congeners. Environ. Sci. Technol. 18: 468-476.

Newbold, J.D., Elwood, J.W., O'Neill, R.V., and Sheldon, A.L. 1983. Phosphorus dynamics in a woodland stream ecosystem: a study of nutrient spiralling. Ecology, 64: 1249-1265.

Nyman, M., Koistinen, J., Fant, M.L., Vartiainen, T., and Helle, E. 2002. Current levels of DDT, PCB and trace elements in the Baltic ringed seals (Phoca hispida baltica) and grey seals (Halichoerus grypus). Environ. Pollut. 119: 399-412.

Nyström, P., and McIntosh, A.R. 2003. Are impacts of an exotic predator on a stream food web influenced by disturbance history? Oecologia, 136: 279-288.

Nyström, P., McIntosh, A.R., and Winterbourn, M.J. 2003. Topdown and bottom-up processes in grassland and forested streams. Oecologia, 136: 596-608.

Ohlsson, K.E.A., and Wallmark, P.H. 1999. Novel calibration with correction for drift and non-linear response for continuous flow isotope ratio mass spectrometry applied to the determination of $\partial{ }^{15} \mathrm{~N}$, total nitrogen, $\partial{ }^{13} \mathrm{C}$ and total carbon in biological material. Analyst, 124: 571-577.

Peterson, B.J., and Fry, B. 1987. Stable isotopes in ecosystem studies. Annu. Rev. Ecol. Syst. 18: 293-320.

Peterson, B.J., Hobbie, J.E., Hershey, A.E., Lock, M.A., Ford, T.E., Vestal, J.R., McKinley, V.L., Hullar, M.A.J., Miller, M.C., Ventullo, R.M., and Volk, G.S. 1985. Transformation of a tundra river from heterotrophy to autotrophy by addition of phosphorus. Science (Wash., D.C.), 229: 1383-1386.

Post, D.M. 2002. Using stable isotopes to estimate trophic position: models, methods, and assumptions. Ecology, 83: 703-718.

Rayne, S., Ikonomou, M.G., and Antcliffe, B. 2003. Rapidly increasing polybrominated diphenyl ether concentrations in the Columbia River system from 1992 to 2000. Environ. Sci. Technol. 37: 2847-2854.

Rosemond, A.D., Mulholland, P.J., and Brawley, S.H. 2000. Seasonally shifting limitation of stream periphyton: response of algal populations and assemblage biomass and productivity to variation in light, nutrients, and herbivores. Can. J. Fish. Aquat. Sci. 57: 66-75.

Russell, R.W., Lazar, R., and Haffner, G.C. 1995. Biomagnification of organochlorines in Lake Eire white bass. Environ. Toxicol. Chem. 14: 719-724.

Schulz, D.E., Petrick, G., and Duinker, J.C. 1989. Complete characterization of polychlorinated biphenyl congeners in commercial Aroclor and Clophen mixtures by multidimensional gas chromatography - electron capture detection. Environ. Sci. Technol. 23: 852-859.

Sijm, D.T.H.M., Seinen, W., and Opperhuizen, A. 1992. Life-cycle biomagnification study in fish. Environ. Sci. Technol. 26: 2162 2174 . 
Skoglund, R.S., and Swackhamer, D.L. 1999. Evidence for the use of organic carbon as the sorbing matrix in the modeling of PCB accumulation in phytoplankton. Environ. Sci. Technol. 33: $1516-1519$

Sokal, R.R., and Rohlf, F.J. 1995. Biometry: the principles and practice of statistics in biological research. 3rd ed. W.H. Freeman and Company, New York.

Stewart, A.J., Hill, W.R., and Boston, H.L. 1993. Grazers, periphyton and toxicant movement in streams. Environ. Toxicol. Chem. 12: 955-957.

Sutcliffe, D.W., Carrick, T.R., and Willoughby, L.G. 1981. Effects of diet, size, age and temperature on growth rates in the amphipod Gammarus pulex. Freshw. Biol. 11: 183-214.
Taylor, W.D., Carey, J.H., Lean, D.R.S., and McQueen, D.J. 1991. Organochlorine concentrations in the plankton of lakes in southern Ontario and their relationship to plankton biomass. Can. J. Fish. Aquat. Sci. 48: 1960-1966.

Thorp, J.H., and Delong, A.D. 2002. Dominance of autochthonous autotrophic carbon in food webs of heterotrophic rivers. Oikos, 96: 543-550.

Vannote, R.L., Minshall, G.W., Cummins, K.W., Sedell, J.R., and Cushing, C.E. 1980. River Continuum Concept. Can. J. Fish. Aquat. Sci. 37: 130-137.

Zaranko, D.T., Griffiths, R.W., and Kaushik, N.K. 1997. Biomagnification of polychlorinated biphenyls through a riverine food web. Environ. Toxicol. Chem. 16: 1463-1471. 